\title{
Desubjetivação na lírica portuguesa: do desassossego de Bernardo Soares às antropofagias de Herberto Helder
}

\author{
Rogério Barbosa da Silva* \\ RESUMO
}

O artigo realiza uma leitura de poemas do Livro do desassossego, de Bernardo Soares/Pessoa em contraponto com as Antropofagias, de Herberto Helder, refletindo sobre o estatuto do sujeito e os processos da lírica portuguesa na contemporaneidade. É de se observar, por exemplo, as tensões do pensamento de Soares/Pessoa em torno das heranças românticas e o desencanto de um sujeito moderno. Por outro lado, é visível a força de um pensamento poético em Helder, uma distinta singularidade que mescla os reinos animal e mineral, identificando o corpo com a matéria e as formas: uma espécie de interminabilidade, múltiplos planos que possibilitam ver ao mesmo tempo as coisas e seu reverso.

Palavras-chave: Livro do desassossego. Herberto Helder. Lírica portuguesa contemporânea.

Mas vibra alguma alma com as minhas palavras? Ouve-as alguém que não sou eu? (PESSOA, 2004, p. 98

e o prazer de maquinar o universo numa restrita organização de linhas vividas em "iminência"

de imagem em imagem se transfere o corpo sempre à beira de "ser" e parando e continuando e ainda "apagando e recomeçando" como se continuamente bebesse de si e tivesse o ar pequeno para demonstrar a grandeza de si a si mesmo (HELDER, 2009, p. 284).

Escrito entre 1913 e os anos 1930 e assinado por Bernardo Soares, mas também pela implicação de outros autores em sua gênese, o Livro do desassossego constitui um modelo exemplar de narrativa poética fragmentada, elíptica, errática, cujos traços têm muito das poéticas que nos são mais contemporâneas, seja numa perspectiva cronológica, seja na assimilação das características dominantes numa * Centro Federal de Educação Tecnológica de Minas Gerais - CEFET - MG 
era pós-moderna. Essa assimilação chega a ser apontada por Richard Zenith, em sua introdução ao Livro do desassossego: "o que temos aqui não é um livro mas a sua subversão e negação, o livro em potência, o livro em plena ruína, o livrosonho, o livro-desespero, o antilivro, além de qualquer literatura." (ZENITH, 2004, p. 13). E mais adiante:

o mundo todo reduzido a fragmentos que não fazem um verdadeiro todo, apenas texto sobre texto sobre texto sem nenhum significado e quase sem nexo - todo este sonho ou pesadelo pós-modernista não foi, para Pessoa, um grandioso discurso. Foi a sua íntima experiência e tênue realidade. (ZENITH, 2004, p. 13).

Apesar de nos situarem no contexto da pós-modernidade, essas observações de Zenith nos recordam também a experiência radical de Mallarmé em Le livre naquilo que continha de esboço de um livro infinito, por isso utópico. Isso não parece estranho à proposta estética de Fernando Pessoa/Bernardo Soares, quando propõe, em carta a Adolfo Casais Monteiro, que a organização de seu livro se baseie "numa escolha, rígida quanto possível, dos trechos variadamente existentes, adaptando, porém, os mais antigos, que falhem à psicologia de Bernardo Soares" (PESSOA, 2004, p. 505).

Quer dizer, as contradições internas da persona de seu suposto autor, o inacabado, a convivência entre o "rígido" e o caótico na organização, derivada da inconstância da psicologia de Soares, bem como o descompasso observado no estilo, entre o "grandioso" e comezinho nas observações de Bernardo Soares, vivendo a banalidade que cerca a rua dos Douradores, são aspectos que podem tornar o Livro do desassossego "o armazém publicado do impublicável". (PESSOA, 2004, p. 505).

São também aspectos que marcam essa "obra" working progress, escrita ao longo de vários anos e cuja configuração atual ultrapassou a vida do seu autor, na medida em que as atuais edições incorporaram mais de quatrocentos fragmentos em relação aos doze publicados em vida por Fernando Pessoa/Bernardo Soares. Refletindo sobre tais feitos editoriais, e apontando o aspecto irrealizado do livro, tal como o deixou o autor, Gustavo Rubim ressalta que o editor "parte de onde Pessoa ficou e, salvo acidente ou desistência, irá conseguir o que ele nunca alcançou: um livro." (RUBIM, 2000, p. 17)

As questões relativas ao plano da enunciação e da autoria são também intrínsecas à gênese da obra, e a complexidade se evidencia nas diversas anotações de Pessoa incorporadas às sucessivas edições, com o surgimento de figuras ficcionais a assinarem os textos, a exemplo do Barão de Teive, de Vicente Guedes, de Bernardo 
Soares. Num Prefácio às Fiç̧ões do interlúdio, Pessoa procura marcar diferenças subjetivas e estilísticas que acompanham as personas que assinam os seus textos, personalidades, mais do que heterônimos. $\mathrm{O}$ autor adverte que

O ajudante de guarda-livros Bernardo Soares e o Barão de Teive são ambos figuras minhamente alheias - escrevem com a mesma substância e estilo, a mesma gramática, e o mesmo tipo e forma de propriedade: é que escrevem com o estilo que, bom ou mau, é o meu. (...) Mas ao passo que o português é igual no Barão de Teive e em Bernardo Soares, o estilo difere em que o do fidalgo é intelectual, despido de imagens, um pouco, como direi?, hirto e restrito; e o do burguês é fluido, participando da música e da pintura, pouco arquitectural. (PESSOA, 2004, p. 506).

Mas ao mesmo tempo em que estabelece tais distâncias, os textos se deixam contaminar pela ambiguidade, uma vez que suas personalidades convertem-se em verdadeiros alteregos umas das outras, como se mostra no Prefácio que abre o Livro do desassossego. Nele, Pessoa apresenta a figura de Bernardo Soares, e nos sugere haver acontecido uma conversa sobre Orpheu, elogiada por Soares, que se revela um dos poucos a que ela se destina. Ao final, o prefaciador revela que o sempre distante e solitário Soares só se aproximara de si com o fim de que ele lhe publicasse o livro, e conclui: "A té nisto - é curioso descobri-lo - as circunstâncias, pondo ante ele quem, do meu caráter, lhe pudesse servir, lhe foram favoráveis." (PESSOA, 2004, p. 41).

Esse jogo que se estabelece na trama textual nos faz lembrar a observação de Luiz Costa Lima, em "Persona e sujeito ficcional", quando lembra que o ficcional "desvia-se da persona de seu agente, seu autor, possibilitando que ele se veja a distância". (LIMA, 1993, p. 51). Trata-se de um processo de atualização crítica operada pelo texto ficcional, que realiza a sua vocação, não pela revelação de verdades, mas por colocar em questão a vida das personae:

A consciência deste deslocamento, pelo qual provisoriamente se abandona a janela da persona para que se ganhe distância quanto a ela, é sutil e indispensável. (Mais do que isso, não é indicador de inevitável resgate: posso descolar-me de meu papel para que seja meu próprio voyer. Não é sempre que o autodistanciamento provoca o voyant). Seu êxito é dificultado pela própria proximidade com a experiência genérica da persona-papel. O vir a cultivar a mão esquerdca, como se diz no poema de Cabral, porque a direita estava demasiado sabida, é uma estratégia muitas vezes necessária contra a proximidade excessiva da persona. (LIMA, 1993, p. 51) 
Algo muito semelhante é afirmado pelo narrador do Livro do desassossego, no fragmento 114, intitulado "Estética do artifício":

Eu próprio não sei se este eu, que vos exponho, por estas colegantes páginas fora, realmente existe ou é apenas um conceito estético e falso que fiz de mim próprio. Sim, é assim. Vivo-me esteticamente em outro. Esculpi a minha vida como a uma estátua de matéria alheia ao meu ser. Às vezes não me reconheço, tão exterior me pus a mim, e tão de modo puramente artístico empreguei a minha consciência de mim próprio. (PESSOA, 2004, p. 138-9).

Essa matéria alheia é, certamente, um modo de se outrar, o que nos leva a pensar a escrita como uma forma de esquecimento, de ignorar a vida, tal como afirmará no fragmento 116 (PESSOA, 2004, p. 140). Mas ser outro é ter uma consciência crítica que de alguma forma implicará um renascimento permanente do sujeito, como se coloca no fragmento 94: "Amanhã o que for será outra coisa, e o que eu vir será visto por olhos recompostos, cheios de uma nova visão". (PESSOA, 2004, p. 124).

Mas, como a nota predominante deste Livro do desassossego é a inquietação, a incerteza, no dizer do próprio Fernando Pessoa, acompanhamos também a desconfiança de Bernardo Soares quanto à possibilidade de um autor se fazer portador da palavra de outrem, ou de que a escrita seja capaz de representar as aspirações do homem comum:

Escrevo, triste, no meu quarto, quieto, sozinho como sempre tenho sido, sozinho como sempre serei. E penso se a minha voz, aparentemente tão pouca coisa, não encarna a substância de milhares de vozes, a fome de dizerem-se de milhares de vidas, a paciência de milhões de almas submissas como a minha ao destino quotidiano, ao sonho inútil, à esperança sem vestígios. (PESSOA, 2004, p. 50).

E se ocorre de a condição de poeta lhe permitir, com esses pensamentos, um viver maior, sentir-se uma espécie de antena da raça, a inteligência lhe fará perceber a vida vã sem beleza e o cigarro barato, arrematando então ironicamente: "Aqui eu, neste quarto andar, a interpelar a vida!, a dizer o que as almas sentem!, a fazer prosa como os gênios e os célebres! Aqui, eu, assim!...” (PESSOA, 2004, p. 50)

Para Soares, não há qualquer redenção na escrita, nem sequer esperança. Como "pregador da renúncia", afirma, escreve porque não aprendeu ainda a executá-la. Seu castigo é saber que o que escreve resulta algo falho, incerto. Se 
há a consciência de que somos explorados, há que se perguntar se valerá menos a pena ser explorado pelo "Vasquez das fazendas" (porque todos temos um patrão Vasquez) ou se pela vaidade, pela glória, pela inveja ou pelo impossível (PESSOA, 2004, p. 51). Assim, se é impossível abdicar da escrita, resta-lhe uma consciência que é contínua inquietação:

Nada me satisfaz, nada me consola, tudo - quer haja sido, quer não - me sacia. Não quero ter a alma e não quero abdicar dela. Desejo o que não desejo e abdico do que não tenho. Não posso ser nada nem tudo: sou a ponte de passagem entre o que não tenho e o que não quero. (PESSOA, 2004, p. 231).

Ao desencanto do sujeito ensimesmado do Livro do desassossego, perambulando "entre o bric-a-brac dos arredores, apreçado pelo peso entre os pós-escritos do perdido", é possível contrapor uma outra forma de subjetivação presente na lírica portuguesa contemporânea. Mas antes convém justificar de se escolher tratar como lírica duas obras díspares na forma como são o Livro do desassossego e as Antropofagias, de Herberto Helder. Apesar de Bernardo Soares declarar-se, no fragmento 227, incapaz de escrever em verso (PESSOA, 2004, p. 228), talvez uma das maneiras de se opor ao Pessoas de Fiç̧ões do interlúdio, ou mesmo aos heterônimos de quem tende a se aproximar, há uma defesa da prosa que muito se aproxima da poesia realizada pela obra pessoana:

Há ritmos verbais que são bailados, em que a ideia se desnuda sinuosamente, numa sensualidade translúcida e perfeita. E há também na prosa subtilezas convulsas em que um grande actor, o Verbo, transmuda ritmicamente em sua substância corpórea o mistério impalpável do universo. (PESSOA, 2004, p. 228)

Assim, considera-se que a biografia sem fatos, ou a história sem vida de Soares constitui uma poiesis através desse discurso inacabado e infinito, com o qual se pode também atravessar não só a obra pessoana, como a tradição lírica portuguesa. Assim também o é Antropofagias, de Herberto Helder, no qual é visível a força de um pensamento poético, uma distinta singularidade que mescla os reinos animal e mineral, identificando o corpo com a matéria e as formas. Em sua poesia uma espécie de interminabilidade deixa-nos perceber múltiplos planos que possibilitam ver ao mesmo tempo as coisas e seu reverso. Além disso, os poemas de Herberto Helder exploram também as cadências discursivas, permitindo-se um acúmulo de imagens que descentram a si mesmas e ao discurso que as mobiliza. 
Antropofagias se estrutura como um conjunto de 12 "textos", tal como se intitulam. Neles, fusiona-se sujeito e objeto, de modo que a voz sofre uma inflexão, alerta o poeta, e as palavras, como autômatos, andam umas com as outras, criando uma espécie de "cinema de palavras".

Logo no primeiro texto de Antropofagias o poeta mostra-nos que essa poesia evita o símile e torna-se ela própria um ato poético: uma imagem-corpo com suas digestões, dilatações e movimentações. Sem se apoiar em moldes (até porque para isso eles teriam de preexistir), o poeta nega o valor simbólico da linguagem: "não tentamos criar abóboras com a palavra 'abóboras'/não é um sentido propiciatório da linguagem" (HELDER, 2009, p. 273). Cede o "entusiasmo arbitrário" os gestos inaugurais da linguagem para que as palavras possam ser vistas como um corpo - respiração digestação dilatação movimentação. (HELDER, 2009, p. 274). Ao assim proceder, o risco iminente de destruição invade o texto: "se calhar vão destruir -nos sob o título/ 'os autômatos invadem' mas invadem o quê?" (HELDER, 2009, p. 274). Conforme afirma Ana Guerreiro,

Para Herberto Helder, o poder regenerador do canibalismo é perpetuado "por dentro de poemas". (Helder, 2006a: 153). Eles contêm, assim, um poder simultaneamente destruidor e salvífico. $\mathrm{O}$ acto antropofágico é uma situação excepcional que confronta o Homem consigo mesmo, expondo-lhe, no corpo da vítima, a sua própria fragilidade e permitindo-lhe, na devoração, uma vitória contra a morte. Também o poeta que se olha a si próprio em Antropofagias se encontra nesse limite da sobrevivência. Vive da observação de actos alimentares encadeados em que o poeta, o poema e o leitor são definidos por máscaras canibalescas. (GUERREIRO, 2009, p. 12).

A ideia de uma prática antropofágica se espraia sobre o texto em que o corpo se deixa ver como uma pulsação viva e convite à alimentação canibalesca: "falanges falanginhas falangetas no 'tabaco terreno'/ a pulsar/ "linguagem" extenuante pela sua própria verdade"” (HELDER, 2009, p. 286). Autor/texto e leitor se consumam nesse rito canibalesco:

O texto: "o corpo com todas as "incursões" caligráficas/ "referências" florais "desvios" ortográficos da família dos carnívoros/ "antropofagias" gramaticais e "pègadas"/ ainda ferventes” (HELDER, 2009, p. 279)

O autor: "agarra-se a esse "destino" a "personagem" saída/ do "trabalho das palavras" dobra-se sobre esse medo/ esse pasmo e alegria essa antropófaga festa/de "estar sobre si" e de essa obscura 
dominação/de "estar em cima dela"/ polpa asfixiando o caroço e agora o caroço/ cancro de frias nervuras fortes tão "praticável"/ a "cena" em que os doces buracos se abrem ao veneno/ essa "troca" de malevolência íntima e energia íntima" (HELDER, 2009, p. 292) O leitor: "um morto veloz na maneira de pôr os dedos/ sobre a "escrita impossível"/ treinara o medo como se faz como uma foca/ tinha uma cabeça muito boa para isso/ e o medo apanhava no ar o seu peixe cruamente alimentar" (HELDER, 2009, p. 293)

No último texto, o eu descreve o suicídio de um poeta e de uma poética, antropofágica, em "que o corpo permitisse o corpo", o que resulta, no outro lado da agonia, "um 'texto monstruoso' que se decifrava/ apenas 'a si próprio"” (HELDER, 2009, p. 295). É esse "excesso corporal” resultante de sua poética transgressora que o poeta oferta em banquete ao leitor. A contradição, conforme anota Ana Lúcia Guerreiro, é que o poeta sobrevive à sua própria morte. (GUERREIRO, 2009, p. 14). Eis como o poeta se descreve em sua experiência transgressora:

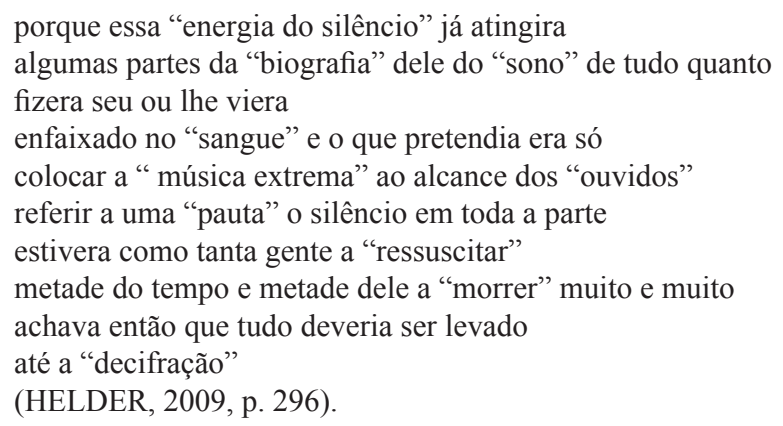

Como podemos verificar, a "festa antropofágica" promovida pelo poema possibilita uma troca de energia que possibilita ao poeta, ao texto e ao leitor continuarem. Assim, o texto é ao mesmo tempo o mecanismo propiciador da festa, o que conduz as energias, mas também o espaço dos despojos, o apropriado e o que the vem enfaixado em sangue. O que importa é que essa poética busca entrar no silêncio para que se possa ouvir a "música extrema". Mas essa poética permite, por sua vez, o apagamento do eu, o apagamento do real, ou do mundo: "no mundo que não havia".

Para concluir, observamos que, como demonstram essas duas poéticas bastante singulares na tradição lírica portuguesa, continuam a questionar o estatuto do sujeito como forma de questionar o mundo exterior. Ao que nos parece, a poética de Herberto Helder parece querer levar ao extremo realizável o que desejava Fernando Pessoa por via das deambulações filosóficas de Bernardo Soares, quando dizia no fragmento 27: 
A literatura, que é a arte casada com o pensamento e a realização sem a mácula da realidade, parece-me ser o fim para que deveria tender todo o esforço humano, se fosse verdadeiramente humano, e não uma superfluidade do animal. (PESSOA, 2004, p. 63).

Percebe-se que a proposta inerente à poética de Herberto Hélder procede a um deslocamento, seja no plano discursivo seja no posicionamento do sujeito no cerne da linguagem, desierarquizando os planos que instituem a comunicação.

\begin{abstract}
This article conducts a reading of poems O Livro do Desassossego, Bernardo Soares/Fernando Pessoa in relating it to the Antropofagias of Herberto. Discusses the status of the subject and processes in Contemporary Portuguese Poetry. It should be noted, for example, strains of thought Soares / Pessoa around the romantic heritage and disenchantment of a modern subject. On the other hand, clearly the strength of a poetic thought in Herberto Helder, a distinct uniqueness that merges the animal and mineral realms, identifying the body with matter and forms: a kind of not terminally, or multiple plans that allow simultaneously see the things and its reverse.
\end{abstract}

Keywords: Livro do desassossego. Herberto Helder. Contemporary portuguese poetry.

\title{
Referências
}

BORTOLI, Ana Paula de \& WINTER, Lígia Maria. Um cifra três vezes alheia: o alheamento poético, editorial e tradutório no Livro do Desassossego, de Fernando Pessoa. In: Revista de Criação e Crítica. São Paulo: USP, n. 5, 36-61, out. 2010. Disponível em $<$ http://revistas.usp.br/criacaoecritica/article/view/46808 $>$. Acesso em 18 nov 2013.

GUERREIRO, Ana Lúcia. A "antropófaga festa". Metáfora para uma ideia de poesia em Herberto Helder. In: Diacrítica. Revista do Centro de Estudos Humanísticos. Braga: Universidade do Minho, n. 23/3, p. 9-22, 2009.

HELDER, Herberto. Antropofagias. In: HELDER, H. Ofício cantante - poesia completa. Lisboa: Assírio \& Alvim, 2009. p. 271-296.

LIMA, Luiz Costa. Persona e sujeito ficcional. In: LIMA, Luiz Costa. Pensando nos trópicos (dispersa demanda II). Rio de Janeiro: Rocco, 1991. p. 40-56. 
MARTINS, Fernando C. Editar Bernardo Soares. In: Revista Colóquio Letras. Lisboa, n. 155-156, p. 220-225, jan 2000. Disponível em <http://coloquio.gulbenkian.pt/bib/sirius.exe/issueContentDisplay? $n=155 \& p=220 \& o=p>$

PESSOA, Fernando. Livro do desassossego - por Bernardo Soares, ajudante de guarda-livros na cidade de Lisboa. Organização de Richard Zenith. $2^{\mathrm{a}}$ ed, $3^{\mathrm{a}}$ reimpressão. São Paulo: Companhia das Letras, 2004.

RUBIM, Gustavo. Livro: o único, o múltiplo, o inexistente. In: Revista Colóquio Letras. Lisboa, n. 155-156, p. 216-219, jan 2000. Disponível em $<$ http:// coloquio.gulbenkian.pt/bib/sirius.exe/issueContentDisplay? $n=155 \& p=216 \& 0=r>$ ZENITH, Richard. Introdução. In: PESSOA, Fernando. Livro do desassossego por Bernardo Soares, ajudante de guarda-livros na cidade de Lisboa. Organização de Richard Zenith. $2^{\mathrm{a}}$ ed, $3^{\mathrm{a}}$ reimpr. São Paulo: Companhia das Letras, 2004. p. 11-41. 
